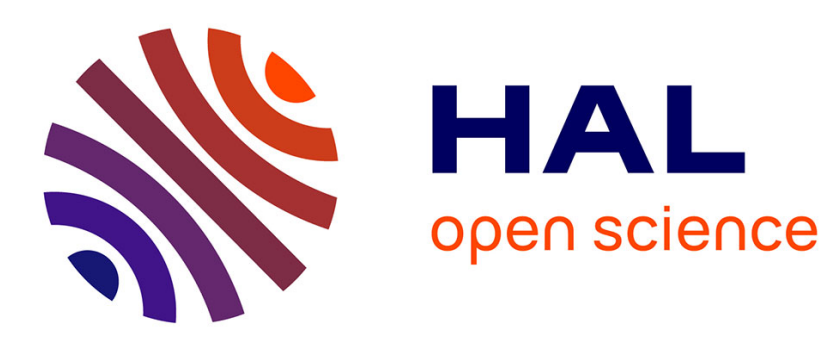

\title{
Il y a 100 ans : glands de Chêne pédonculé et glands de Chêne rouvre
}

- [.]revue Forestière Française, Rédaction

\section{To cite this version:}

- [.]revue Forestière Française, Rédaction. Il y a 100 ans : glands de Chêne pédonculé et glands de Chêne rouvre. 1992, pp.189-190. 10.4267/2042/26313 . hal-03535288

\section{HAL Id: hal-03535288 \\ https://hal.science/hal-03535288}

Submitted on 19 Jan 2022

HAL is a multi-disciplinary open access archive for the deposit and dissemination of scientific research documents, whether they are published or not. The documents may come from teaching and research institutions in France or abroad, or from public or private research centers.
L'archive ouverte pluridisciplinaire HAL, est destinée au dépôt et à la diffusion de documents scientifiques de niveau recherche, publiés ou non, émanant des établissements d'enseignement et de recherche français ou étrangers, des laboratoires publics ou privés. 


\section{IL Y A 100 ANS GLANDS DE CHÊNE PÉDONCULÉ ET GLANDS DE CHÊNE ROUVRE}

Distinguer les uns des autres les glands de nos deux grands Chênes classiques est très souvent nécessaire, pour les raisons que nos lecteurs connaissent bien.

Cela n'est pas toujours facile au premier abord: on en discute souvent encore aujourd'hui, et les chercheurs ne sont pas en reste ${ }^{(1)}$.

Un article paru dans le numéro de novembre 1892 de la Revue des Eaux et Forêts (pages 512513) se faisait déjà fort de lever le doute; en voici l'essentiel:

"Nous allons indiquer un moyen de les distinguer. Dans la forêt de Bercé (Sarthe), où le rouvre couvre presque toute la surface et où l'on ne rencontre le pédonculé que très rarement dans le massif et quelquefois sur les lisières, la question est importante. La futaie de rouvre est magnifique, le pédonculé ne vient pas ou vient mal et les sujets en sont défectueux; dans tout le voisinage, au contraire, on peut même dire dans toute la Sarthe (la forêt de Perseigne exceptèe), que ce soit dans les haies ou dans les forêts, c'est le pédonculé que l'on rencontre exclusivement; les ramasseurs de glands, payés à tant l'hectolitre par l'administration, apportent dans les magasins du gland ramassé dans le massif domanial et aussi du gland des arbres de haie, plus aisé à recueillir; il faut donc reconnaître la fraude et refuser le pédonculé. Voici les caractères sur lesquels s'appuie le personnel des gardes pour vérifier les fournitures.

Sur le péricarpe, sur l'écorce si l'on veut, du gland de Chêne pédonculé, se trouvent toujours des raies longitudinales, nombreuses, rapprochées, à peu près équidistantes, non interrompues depuis la base du fruit jusqu'au sommet; elles sont minces, 1/2 millimètre au plus; leur coloration est notablement plus foncée que celle du gland lui-même; si le gland est vert, les raies sont d'un vert plus foncé ; à la maturité, lorsque le gland est brun, elles sont nettement plus brunes, presque noires. L'intervalle qui les sépare varie bien entendu avec la grosseur du fruit, il est en moyenne de 3-4 millimètres. Pour la coloration et l'épaisseur, il semble qu'on ne puisse mieux les comparer qu'aux rayons médullaires du bois de Chêne, vus sur une section transversale. Sur le gland de rouvre, rien de semblable; exceptionnellement on trouvera bien sur certains sujets quelques raies, mais celles-ci ne sont jamais aussi nettes que sur le pédonculé ; de plus, elles ne se continuent pas de la base au sommet et elles sont bien moins apparentes; enfin, sur la plus grande partie des graines, on n'en voit pas du tout. Avec un peu d'habitude, on trouve les raies du pédonculé si visibles que sur un amoncellement de glands, il est inutile de se baisser pour distinguer les uns des autres.

(1) Lire par exemple: Dupouey (J.-L.), Le Bouler (H.). - Discrimination morphologique des glands de Chêne sessile et pédonculé. - Annales des Sciences forestieres, $n^{\circ} 2,1989$, pp. 187-194 (avec bibliographie). 
Nous ignorons si, dans d'autres forêts, ces caractères sont aussi tranchés qu'à Bercé; ce que nous pouvons affirmer, c'est qu'à la suite de nombreuses expériences effectuées depuis 6 ans, après avoir cueilli nous-même des glands à la fois sur des chênes pédonculés et sur des chênes rouvres, nous avons toujours retrouvé les différences que nous venons de signaler.

/l serait utile de vérifier cette distinction dans d'autres massifs".

(ROULLEAU)

C'était il y a cent ans, nous voici en 1992.

Parmi les forestiers, les pépiniéristes des Chênes du temps présent, qui confirmera, ou bien infirmera cette observation? 